\title{
Decomposing oceanic temperature and salinity change using ocean carbon change
}

\author{
Charles Turner ${ }^{1}$, Peter Brown ${ }^{2}$, Kevin Oliver ${ }^{1}$, and Elaine L. McDonagh ${ }^{2,3}$ \\ ${ }^{1}$ University of Southampton, European Way, Southampton, SO14 3ZH \\ ${ }^{2}$ National Oceanography Centre, European Way, Southampton, SO14 3ZH \\ ${ }^{3}$ NORCE Norwegian Research Centre, Bjerknes Centre for Climate Research, Bergen, Norway
}

Correspondence: Charles Turner (charles.turner@ soton.ac.uk)

\begin{abstract}
As the planet warms due to the accumulation of anthropogenic $\mathrm{CO}_{2}$ in the atmosphere, the global ocean uptake of heat can largely be described as a linear function of anthropogenic $\mathrm{CO}_{2}$ uptake. This relates the oceans mitigation of atmospheric warming and carbon sequestration, as well as its increasing heat content. Patterns of ocean salinity also change as the earth system warms due to hydrological cycle intensification and perturbations to air-sea freshwater fluxes. Local temperature and salinity change in the ocean may result from perturbed air-sea fluxes of heat and freshwater (excess temperature, salinity), or from variability resulting from reorganisation of the preindustrial temperature and salinity fields (redistributed temperature, salinity), which are largely due to circulation changes. Here, we present a novel method in which by tracking the redistribution of preindustrial carbon, we may estimate the redistribution of temperature and salinity using only local spatial information. We demonstrate this technique by estimating the redistribution of heat and salinity in the NEMO OGCM coupled to the MEDUSA2 Biogeochemistry model under a RCP8.5 scenario over 1860-2099. We find on the longest timescales, the patterns of excess heat and salinity storage are dominated by increases in excess heat and salinity in the Atlantic, and that excess salinity is generally negative in other basins, compensating for strong atmospheric transport of excess salinity to the Atlantic.
\end{abstract}

We also find significant redistribution of heat away from the North Atlantic, and of salinity to the South Atlantic, consistent with AMOC slowdown. Temperature change at depth is accounted for predominately by redistributed, rather than excess heat, but the opposite is true for salinity, where the excess component accounts for the majority of changes at depth.

Though by the end of the simulation excess heat is the largest contribution to density change and steric sea level rise, the storage of excess salinity greatly reduces variability in excess density, particularly in the Atlantic. Here, redistribution of the preindustrial heat and salinity fields also produce generally opposing changes in sea level, though patterns are less clear elsewhere.

As expected, the regional strength of excess heat and salinity signal grows through the model run. In addition, the regional strength of the redistributed temperature and salinity signals also grow, indicating increasing circulation variability or systematic circulation change on at least the time scale of the model run. 
https://doi.org/10.5194/os-2021-54

Preprint. Discussion started: 14 June 2021

\section{Introduction}

The planet continues to warm due to anthropogenic $\mathrm{CO}_{2}$ accumulation in the atmosphere. However, the ocean acts to mitigate climate change, having absorbed a third of all $\mathrm{CO}_{2}$ emissions to date (Khatiwala et al., 2013), as well as over $90 \%$ of the additional heat accumulating in the Earth system (Church et al., 2011). Though this greatly slows the rate of surface warming, it is not without consequence: as a result of the excess heat content, global sea levels are expected to rise significantly over the coming centuries due to the thermal expansion of seawater (Pardaens et al., 2011), with enormous implications for future economic development (Hinkel et al., 2014).

The ocean heat and carbon uptakes are intimately linked through the radiative forcing of $\mathrm{CO}_{2}$ and the oceans ability to sequester atmospheric $\mathrm{CO}_{2}$ (Bronselaer and Zanna, 2020), (Goodwin et al., 2015), resulting in a near linear relationship between the response of the ocean to increasing atmospheric temperatures and $\mathrm{CO}_{2}$ levels. This allows us to leverage our understanding of changes to the ocean carbon cycle to study changes in ocean heat content and circulation.

The warming earth system also drives changes in the hydrological cycle - consequent regional variability in ocean salinity driven by perturbations to air-sea freshwater fluxes (such as evaporation and precipitation) is described here as the excess salinity field. Regional variability in temperature and salinity is also driven by reorganisation of the temperature and salinity field, such as by circulation changes, described here as redistributed variability. In the past the redistributed components of change have dominated over the excess (Zika et al., 2021), (Bronselaer and Zanna, 2020) but the excess temperature field will become increasingly important in the future, while the excess salinity field is less well understood and studied. Regional sea level rise is impacted by not only by the local component of excess temperature, but also local excess salinity, redistributed temperature change, and redistributed salinity change. Thus it is important to understand the character, distribution and evolution of excess and redistributed temperature and salinity in order to understand their contributions to regional sea level change.

However, in order to reduce uncertainty in our estimates of local, rather than global, sea level rise, it is necessary to understand the causes of local ocean heat content and salinity changes, in a process similar to the identification of anthropogenic carbon $\left(\mathrm{C}_{\mathrm{anth}}\right)$ in the ocean: changes to ocean circulation are a key source of uncertainty in regional sea level rise estimates (Church et al., 2013).

It remains challenging to separate the nature of anthropogenically (or naturally) forced temperature and salinity change in the ocean as we do carbon. While increased carbon content does not alter ocean circulation, changes in the temperature and salinity structure do. As a result, observed temperature and salinity changes may be due to the addition or removal of heat or freshwater (known as excess heat/salinity, and associated with increased radiative forcing) or the rearrangement of the existing temperature/salinity field (known as redistributed heat/salinity). Though distinguishing between these two 'types' of temperature/salinity change is difficult observationally, they are theoretically distinct, and contribute very differently to ocean changes as the planet warms. With the exception of basal ice shelf melt, excess heat and salinity must invade the ocean through the surface, and so significant accumulation of large quantities of excess heat and salinity by the ocean is well represented by the steady state advection of a boundary condition. However, the redistribution of temperature and salinity by the ocean in response to circulation variability acts on much shorter timescales, and contributes the majority of variability in contemporary 
ocean temperature and salinity when approximated using a spice-heave decomposition (Desbruyères et al., 2017), (Bindoff and Mcdougall, 1994). Identifying whether changes in ocean temperature and salinity are due to excess or the redistribution of the preindustrial fields therefore has implications for understanding timescales of sea level rise, as well as both short and longer timescale variability in ocean temperature and salinity.

A similar decomposition may be applied to the increased ocean carbon content: the total dissolved inorganic carbon (DIC), may be separated into two pools: Natural Carbon $\left(\mathrm{C}_{\text {nat }}\right)$, the $\mathrm{DIC}$ which would be found in the global ocean if atmospheric $\mathrm{CO}_{2}$ were to remain at preindustrial levels, and Anthropogenic Carbon $\left(\mathrm{C}_{\mathrm{anth}}\right)$, which enters the ocean as a result of this increasing atmospheric $\mathrm{CO}_{2}$. However, atmospheric $\mathrm{CO}_{2}$ changes, unlike temperature or freshwater flux changes, are approximately globally uniform meaning DIC change can be partitioned into changes in $\mathrm{C}_{\text {nat }}$ and those of $\mathrm{C}_{\text {anth }}(\mathrm{Gruber}$ et al. (1996), Touratier and Goyet (2004), Vázquez-Rodríguez et al. (2009), Hall et al. (2002), Khatiwala et al. (2005)).

Though decomposition of DIC into $\mathrm{C}_{\text {nat }}$ and $\mathrm{C}_{\text {anth }}$ signals remains imperfect (estimates of local $\mathrm{C}_{\text {anth }}$ concentrations can differ significantly depending on the choice of reconstruction (Khatiwala et al., 2013)), it is far more developed than that of decomposing temperature or salinity changes. This allows us to use $\mathrm{C}_{\text {nat }}$ change as a proxy for the redistribution of preindustrial temperature and salinity: redistribution leaves the properties of a parcel of water unchanged, and so we can track the redistribution of temperature and salinity using the redistribution of $\mathrm{C}_{\text {nat }}$. Our method relies only on knowledge of local spatial relationships between temperature or salinity and carbon, rather than a mechanistic relationship (Bronselaer and Zanna, 2020) between the radiative forcing of atmospheric $\mathrm{CO}_{2}$ and the oceans ability to sequester $\mathrm{CO}_{2}$. As a result, our decomposition is not restricted to temperature change only. This allows us to not only produce estimates of temperature redistribution, but also the first estimates (to our knowledge) of salinity, and by extension density, redistribution. Using these, we investigate the patterns of storage of excess and redistributed temperature and salinity by the global ocean.

\section{Data and Methods}

\subsection{Model set up}

80 We use the NEMO v3.2 OGCM (Ocean General Circulation Model) Collins et al. (2011) coupled to the MEDUSA-2 biogeochemical model Yool et al. (2013) and the Louvain-la-Neuve (LIM2) dynamic sea ice model Timmermann et al. (2005), following a RCP8.5 climate change scenario. The model was configured with the ORCA1 grid with a nominal 1 degree resolution and 64 vertical levels. The model was spun up for 900 years, before three 240 year simulations were spawned: a control run (CTR), coupled climate change run (COU), and a 'warming only' run (RAD).

85 The climate change run utilises surface flux output from a HadGEM2-ES earth system model simulation, driven following a RCP 8.5 pathway. The control run was forced with 8 repetitions of the first 30 years of forcing from this simulation, and the 'warming only' run with physical forcing from the climate change run, but with atmospheric $\mathrm{CO}_{2} \mathrm{kept}_{\mathrm{c}} \mathrm{constant}$ at $286 \mathrm{ppm}$. This allows us to calculate $\mathrm{C}_{\text {anth }}$ directly as

$\mathrm{C}_{\mathrm{anth}}=\mathrm{DIC}^{\mathrm{COU}}-\mathrm{DIC}^{\mathrm{RAD}}$ 
https://doi.org/10.5194/os-2021-54

Preprint. Discussion started: 14 June 2021

(c) Author(s) 2021. CC BY 4.0 License.

(c) (i)

$\mathrm{C}_{\text {nat }}$ is then calculated as

$\mathrm{C}_{\text {nat }}=\mathrm{DIC} \mathrm{COU}^{\mathrm{CO}}-\mathrm{C}_{\mathrm{anth}}-\Delta \mathrm{DIC} \mathrm{CTR}^{\mathrm{TT}}=\mathrm{DIC}^{\mathrm{RAD}}-\Delta \mathrm{DIC} \mathrm{CTR}^{\mathrm{T}}$,

where $\Delta \mathrm{DIC} \mathrm{CTR}^{\mathrm{T}}$ is control run drift. As all simulations are spawned from the same spinup, $\mathrm{C}_{\text {nat }}$ change $\mathrm{C}_{\text {nat }}, \Delta \mathrm{C}_{\text {nat }}$, is therefore given by

$\Delta \mathrm{C}_{\text {nat }}=\mathrm{DIC}^{\mathrm{RAD}}-\mathrm{DIC}^{\mathrm{CTR}}$

For further detail on model setup, see Couldrey et al. (2019).

\subsection{Parametrising temperature and salinity change as functions of $\mathrm{C}_{\text {nat }}$ change}

Here, we refer to a general tracer, $Q$, instead of temperature or salinity. Provided both $Q$ and $\mathrm{C}_{\text {nat }}$ are defined over the same domain, we may parametrise $Q$ in terms of $\mathrm{C}_{\text {nat }}$ :

$Q(x, y, z, t)=Q\left(\mathrm{C}_{\text {nat }}\right)=Q\left(\mathrm{C}_{\text {nat }}(x, y, z, t)\right)$

Using the relationship between Eulerian and Lagrangian derivatives:

$d Q=\left(\partial_{t} Q+\mathbf{v} \cdot \nabla Q\right) d t$

we may express the derivative of $Q$ with respect to $\mathrm{C}_{\text {nat }}$ as

$\frac{d Q}{d \mathrm{C}_{\text {nat }}}=\frac{\partial_{t} Q+\mathbf{v} \cdot \nabla Q}{\partial_{t} \mathrm{C}_{\text {nat }}+\mathbf{v} \cdot \nabla \mathrm{C}_{\text {nat }}}$

It is important to note at this point that the term $d Q / d \mathrm{C}_{\text {nat }}$ is not an Eulerian derivative: it is simply a total derivative in $Q-\mathrm{C}_{\text {nat }}$ space. This leads to the result that we may estimate the total derivative $d Q / d \mathrm{C}_{\text {nat }}$ by considering timeseries of two quantities at a fixed geographic location. We now wish to use this relationship in order to decompose the nature of changes in $Q$.

Winton et al. (2013) break the tracer $Q$ and the transport $v$ up as follows:

$v Q=\left(v_{0}+v^{\prime}\right)\left(Q_{0}+Q^{\prime}\right)=\underbrace{v_{0} Q_{0}}_{\text {Preindustrial }}+\underbrace{v^{\prime} Q_{0}}_{\text {Redistributed }}+\underbrace{v_{o} Q^{\prime}+v^{\prime} Q^{\prime}}_{\text {Excess }}$,

where $v_{o}$ and $Q_{0}$ refer to the preindustrial components of $v$ and $Q$, and $v^{\prime}$ and $Q^{\prime}$ the perturbations. We will refer to the component $v^{\prime} Q_{0}$ as the redistributed component, and the components $\left(v_{0}+v^{\prime}\right) Q^{\prime}$ as the excess component of $Q$.

Following Winton et al. (2013), we split the velocity field v, though we decompose our velocity field further:

$\mathbf{v}=\mathbf{v}_{\mathbf{0}}+\mathbf{v}^{\prime}=\overline{\mathbf{v}}+\mathbf{v}_{s}+\mathbf{v}_{l}$

Here, the velocity field is first split into two components: the initial, steady state component, $\mathbf{v}_{0}$, and the perturbation to the

velocity field due to climate change, $\mathbf{v}^{\prime}$. When considering correlations between two variables, it is necessary to split the 
steady state component $\mathbf{v}_{0}$ into the mean steady state flow, $\overline{\mathbf{v}}$, and deviations from this mean flow, $\mathbf{v}_{s}$, which we label the short timescale velocity. We have also relabelled $\mathbf{v}^{\prime}$ to $\mathbf{v}_{l}$ to explicitly identify it with longer time variability in ocean circulation, rather than just deviations from mean flow. Whilst $\mathbf{v}_{s}$ is assumed to be composed mainly of seasonal variability contained in $\mathbf{v}_{0}$ (with zero mean), it may also include changes to the seasonal cycle resulting from climate change.

We now define a new operator, $\bar{d}_{t}$ as follows:

$\bar{d}_{t}=\partial_{t}+\overline{\mathbf{v}} \cdot \nabla=\frac{d}{d t}-\left(\mathbf{v}_{l}+\mathbf{v}_{s}\right) \cdot \nabla$

such that $\bar{d}_{t}$ would be the total derivative, were circulation forced to remain in its mean preindustrial state. The time integral of this quantity therefore approximates the excess. Combining Equations (6) and (9), we obtain

$$
\frac{d Q}{d \mathrm{C}_{\text {nat }}}=\frac{\bar{d}_{t} Q+\left(\mathbf{v}_{s}+\mathbf{v}_{l}\right) \cdot \nabla Q}{\bar{d}_{t} \mathrm{C}_{\text {nat }}+\left(\mathbf{v}_{s}+\mathbf{v}_{l}\right) \cdot \nabla \mathrm{C}_{\text {nat }}}
$$

We now show how this relationship may be leveraged to obtain estimates of excess and redistributed $Q$ from carbon change. On short timescales, we may assume that $\mathbf{v}_{s} \gg \mathbf{v}_{l}$, and $\mathbf{v}_{s} \gg \bar{d}_{t}$ for both $Q$ and $\mathrm{C}_{\text {nat }}$ : that is, seasonal variability far exceeds the accumulation of excess $Q$, or redistribution of $Q$ or $\mathrm{C}_{\text {nat }}$ (excess $\mathrm{C}_{\text {nat }}$ is minimal by construction). On such timescales, the relationship between the two variables is therefore determined entirely by their spatial covariability. We therefore label this quantity the spatial variability coefficient, $\kappa_{s}$ :

$\kappa_{s}^{Q}=\frac{\mathbf{v}_{s} \cdot \nabla Q}{\mathbf{v}_{s} \cdot \nabla \mathrm{C}_{\text {nat }}}$

On sufficiently long timescales, we may assume that seasonal variability averages to zero, and so $\mathbf{v}_{l} \gg \mathbf{v}_{s}$. Therefore, the change in $Q$ due to redistribution $\left(d Q_{r}\right)$, for which $\bar{d}_{t} Q_{r}=0$, is given by

$$
\frac{d Q_{r}}{d \mathrm{C}_{\text {nat }}}=\frac{\mathbf{v}_{l} \cdot \nabla Q}{\mathbf{v}_{l} \cdot \nabla \mathrm{C}_{\text {nat }}}
$$

provided that $\mathrm{C}_{\text {nat }}$ changes only through redistribution. However, due to changes in $\mathrm{C}_{\text {nat }}$ resulting from biological variability and the outgassing of saturation carbon, $\mathrm{C}_{\mathrm{sat}}$, in response to warming, $\mathrm{C}_{\text {nat }}$ does not well satisfy this. In general,

$\frac{d}{d t} \iiint \mathrm{C}_{\text {nat }} d V<0$,

and so we correct for this divergence of $\mathrm{C}_{\text {nat }}$ and the ideal behaviour of a redistributed preindustrial carbon field using a repartitioning factor, which we refer to as $\gamma$, and the corrected quantity as adjusted natural carbon, $\mathrm{C}_{\text {nat }}^{\text {adj }}$. Because of the imperfect representation of changes in redistribution by $\mathrm{C}_{\text {nat }}^{\mathrm{adj}}$ due to biological changes, we enforce the condition that globally integrated redistributed heat is zero in order to calculate $\gamma$. This is described by

$\Delta \Theta_{r}=\kappa_{r}^{T} \Delta \mathrm{C}_{\mathrm{nat}}^{\mathrm{adj}}=\kappa_{r}^{T}\left(\Delta \mathrm{C}_{\mathrm{nat}}+\gamma \mathrm{C}_{\mathrm{anth}}\right)$

where $\gamma$ is a factor between 0 and 1 such that

$\iiint \Delta \Theta_{r} d V=0$ 
We may therefore estimate the change in $Q$ due to redistribution, $\Delta Q_{r}$, as

145

$$
\Delta Q_{r}=S_{u} \kappa_{s}^{Q} \Delta \mathrm{C}_{\mathrm{nat}}^{\mathrm{adj}}=\kappa_{r}^{Q} \Delta \mathrm{C}_{\mathrm{nat}}^{\mathrm{adj}}
$$

where $\kappa_{r}^{Q}$ is our redistribution coefficient, equal to $\kappa_{s}^{Q}$ multiplied by a scale factor $S_{u}$ which accounts for uncertainty in our estimate of redistribution. This requires the condition

$\mathbf{v}_{s} \| \mathbf{v}_{l}$

ie. the long term velocity perturbation is parallel to the seasonal velocity. This condition is quite restrictive, and unlikely to be observed strictly throughout the global ocean. However, it is typically the case that one term in the sum $\mathbf{v} \cdot \nabla Q$ dominates due to the spatial gradients being much larger in one direction - usually $\mathbf{v} \cdot \nabla Q \approx w \partial_{z} Q$. In such cases, $\mathbf{v}_{l}$ can include relatively large contributions from the $u$ and $v$ components without similar components in $\mathbf{v}_{s}$ without issue, as these contributions will be scaled away by the much smaller gradients. In this approximation, this approach to estimating redistribution is conceptually similar to a spice-heave decomposition, but following a $\mathrm{C}_{\text {nat }}$ surface rather than a density surface.

We also note that in Equation (6), replacing $\mathrm{C}_{\text {nat }}$ with the full DIC field and $Q$ with temperature before taking a global mean yields the approach of Bronselaer and Zanna (2020), where excess temperature is estimated from anthropogenic carbon. Thus, the two approaches can be considered to be opposite limits of the same relationship between DIC and temperature: redistributed temperature may be estimated from $\mathrm{C}_{\text {nat }}^{\text {adj }}$, or excess temperature estimated from $\mathrm{C}_{\text {anth }}$.

\subsection{Implementation: Estimating redistribution}

In order to estimate $\kappa_{r}$, we use the first 100 years of yearly mean data from the control run, binned into 10 decades. In each decade, the mean $\Theta$ or $S$ and $\mathrm{C}_{\text {nat }}$ value is subtracted, and the remaining deviations are used to establish a value of $\kappa_{s}$. This is done using Principal Component Analysis (PCA). It was found that correcting for model drift when estimating $\kappa_{s}$ was detrimental to estimates, as it reduces the quality of correlations between the deviations in temperature and carbon. However, it was necessary to correct for model drifts when estimating $\mathrm{C}_{\text {nat }}$ change, as model drifts were of comparable size to the total change in $\mathrm{C}_{\text {nat }}$ over the time period. We then calculate $S_{u}$ based on the quality of the correlations to estimate $\kappa_{r}$ : this process is detailed in Appendix (A). Adjusted $\mathrm{C}_{\text {nat }}$ was then calculated for each year using Equation (16) to satisfy Equation (17), before being smoothed over a 10 year period. Over the 240 year run, $\gamma$ increases from 0 to approximately 0.12 , with an approximately sigmoid shape.

Once the adjusted $\mathrm{C}_{\text {nat }}$ fields had been built, the same adjusted $\mathrm{C}_{\text {nat }}$ field was used to generate both the redistributed temperature and salinity fields: we did not recalculate a new $\gamma$ value to force a zero integral of salinity redistribution. We choose this approach both for consistency, and due to the nature of sea ice melt: the salinity of sea ice in the model (6PSU) and reduced carbon content of sea ice cause some ice melt to be captured as redistributed salinity, rather than excess. This means that we do not expect globally integrated salinity redistribution to sum to zero as we do for temperature.

Estimates of redistributed salinity are complicated in the top $200 \mathrm{~m}$ by the impacts of freshwater dilution, leading to misat- 
using the same $\kappa_{r}$ approach to locally estimate the gradient of the T-S curve. We then estimate the salinity redistribution by multiplying the redistributed temperature field by this local T-S gradient: we refer to this as a two step estimation. The two estimates were then combined using a sigmoidal weighting, exchanging from the two step estimate at the surface to the one step estimate at depth with equal weight at $200 \mathrm{~m}$. This was not found to leave any artefacts in the estimates of salinity redistribution. This process is detailed in Appendix (B).

Excess and redistributed density fields were then built from the decomposed temperature and salinity fields. To do this, we add the redistributed change to the initial fields, and calculate redistributed density using TEOS-10 (McDougall and Barker, 2011). Initial density is then subtracted for density redistribution. Excess density fields are then calculated as the difference between this field and the total density change to avoid nonlinear effects $\left(\Delta \sigma \neq \Delta \sigma_{e}+\Delta \sigma_{r}\right)$.

\section{Results}

\subsection{Inventory Changes}
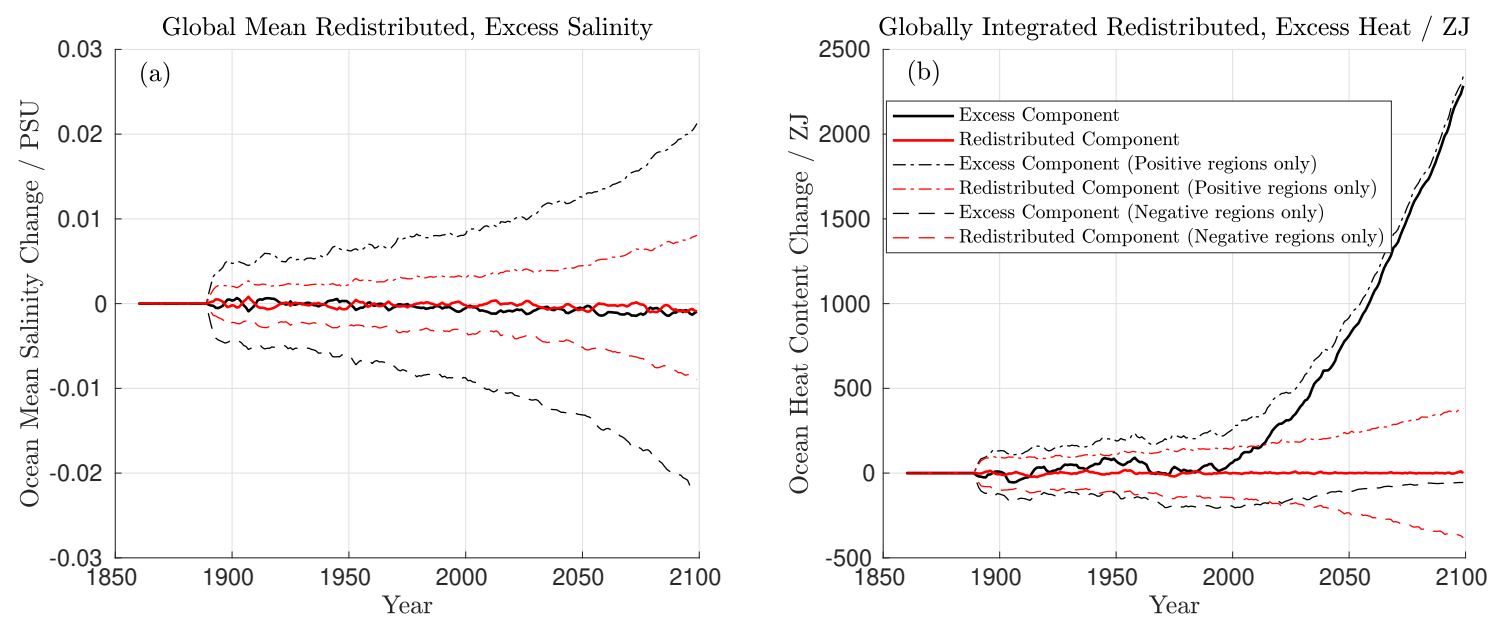

Figure 1. Global mean excess and redistributed salinity (a), and globally integrated excess and redistributed heat (b). Excess components are shown in black, redistributed components in red. The integrals of only the positive and negative regions are also shown (thin dashed lines). Climate change and control runs use the same first 30 years of forcing, so values are by definition zero here: the jump in 1890 represents the initial divergence of states.

Global mean excess and redistributed salinity change, as well as globally integrated excess and redistributed heat content change are shown in Figure 1: excess components are shown in black, and redistributed components in red. The global mean excess and redistributed salinity (thick lines, Figure 1a) begin to decrease immediately, though this decrease is much smaller than the scale of either the excess or redistributed salinity components (thin dashed lines): global mean excess and redistributed salinity both decrease by approximately 0.001PSU over the full run. Globally integrated excess heat does not begin to accumu- 
https://doi.org/10.5194/os-2021-54

Preprint. Discussion started: 14 June 2021

late significantly until approximately 2000: until this point, both positive only (global integral of excess heat content only in regions where excess temperature is positive) and negative only excess and redistributed heat are of similar scales. Positive only excess heat and globally integrated excess heat are approximately the same by 2050, and negative only excess heat increases from approximately $-200 \mathrm{ZJ}$ in 2000 to approximately $-50 \mathrm{ZJ}$ by 2100 : some negative excess heat due to cooling in the first half of the run remains throughout the full simulation.

Whilst excess heat begins to dominate during the mid $21^{\text {st }}$ century, the extent of temperature (and salinity) redistribution continually increases: there is no indication of 'settling' into a new circulation state, where redistribution ceases to increase, on these timescales, and further additions of excess heat continually act to change the circulation. This is in agreement with previous studies, which find excess heat becoming dominant on similar time horizons. We find the global mean excess temperature exceeds the global mean absolute redistributed temperature in the late 2020's. Though a crude metric which does not consider differences in spatial distributions, this indicates that the dominance of excess temperature is likely to occur in the near future.

Figure 2 shows the integrated redistributed and excess temperature, salinity, and densities for each ocean basin. As with the global mean, excess salinity begins to accumulate almost immediately in most ocean basins (Figure 2c). Excess temperature, with the exception of the South Atlantic (Figure $2 \mathrm{a}$, dashed black line) which cools in the $20^{\text {th }}$ century, does not begin to accumulate until the $21^{\text {st }}$ century, at which point it begins to rapidly accumulate in all ocean basins. The accumulation of negative excess density is dominated by the accumulation of excess temperature, rather than salinity: the grey scales on panels (a)-(d) show the associated density change with heat and salinity change. In the North Atlantic, changes in the excess heat and salinity tend to compensate to reduce density anomalies: a reduction of almost $25 \mathrm{Pg}$ associated with excess heat is compensated for by an increase of approximately $8 \mathrm{Pg}$ associated with increased salinity. Similar compensation, though much weaker, is seen in the South Atlantic, but not in other basins, where the changes in excess heat and salinity both act to decrease density.

The redistribution of density is more complicated: redistributed heat and salinity contribute on similar scales to redistributed density. In the North Atlantic, the redistribution of heat and salinity are approximately density compensated until around 2050, at which point the redistributed density component begins to increase rapidly (Figure 2f, black line). Good density compensation in the redistributed component is also seen in the Subantarctic Southern ocean.

In our climate change run, the AMOC strength increases until 1990 before declining thereafter. The cumulative transport anomaly (time integrated difference between climate change and control run AMOC volume transport) peaks in 2035 before declining. This signal is particularly visible in the redistributed heat content of the North Atlantic, which peaks in 2037 before declining rapidly, as well as the redistributed salinity content of the South Atlantic, which begins to increase at approximately the same time. This is consistent with previous studies (Zhu and Liu, 2020) which find a 'pile up' of salinity in the South Atlantic as a result of AMOC slowdown.

As with the global inventories, we find little evidence of 'settling' into a new circulation state: with the exception of the South Pacific and Arctic, the rate of accumulation of excess salinity is either unchanging or increasing throughout the run. This is less clear with redistributed heat: the emergent relationships between excess and redistributed heat inventories are shown in Figure 3. 

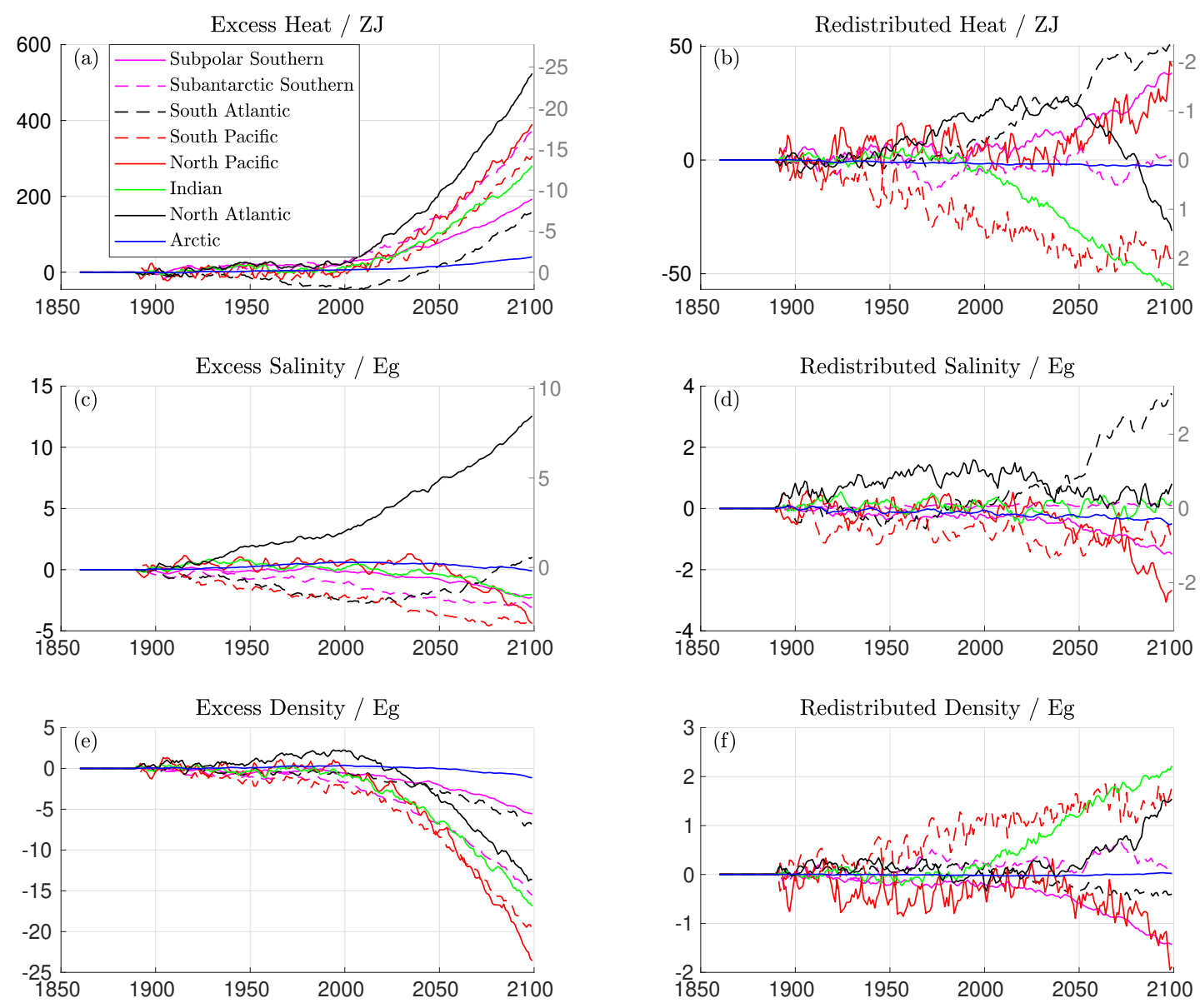

Figure 2. Excess (left column) and redistributed (right) heat, salinity and density integrals for each ocean basin over the full model run. For the changes in heat and salinity (Panels (a)-(d)), the equivalent integrated density change in units of Pg are given in grey on the right. Scales differ for excess and redistributed components, and changes in salinity and density are given as mass changes rather than volumes.

In the North Atlantic, we find an acceleration of the accumulation of redistributed heat with respect to the excess heat inventory. However, in all other basins, we find the rate of accumulation of excess heat outstrips the accumulation of redistributed heat. This is as expected: the acceleration of the accumulation of redistributed heat is unique to the North Atlantic. Other than the North Atlantic, the rate of accumulation of redistributed heat with respect to excess heat slows over the timeseries.

However, we find that of the 8 basins, only four appear to be 'saturated' with respect to redistributed heat: The subantarctic Southern, South Atlantic, South Pacific and Arctic. In all other basins, we see the continued accumulation of redistributed temperature, indicating the continual dynamic readjustment of the ocean, at an inter-basin scale: the lack of growth at a basin 
https://doi.org/10.5194/os-2021-54

Preprint. Discussion started: 14 June 2021

(c) Author(s) 2021. CC BY 4.0 License.
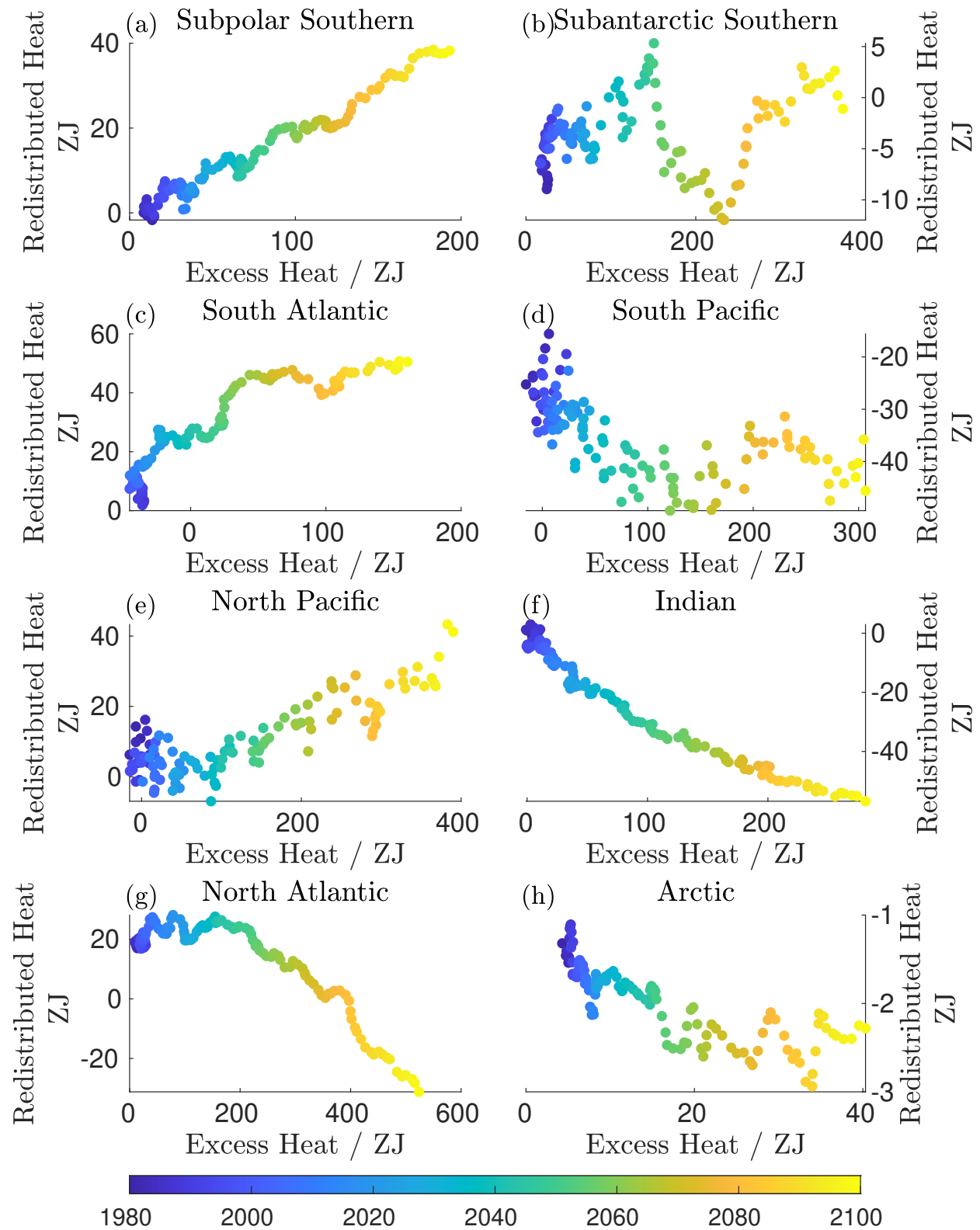

Figure 3. The emergent relationships observed between excess and redistributed heat in each of the 8 ocean basins shown in Figure 2 . Timeseries begin in 1980 as there is no appreciable accumulation of excess or redistributed heat in the first half of the run.

scale imposes no constrains on intra-basin redistribution. Of these, the Subpolar Southern and North Atlantic are perhaps the most striking, with heat redistribution increasing linearly and with the square of excess heat accumulation, respectively. The 
https://doi.org/10.5194/os-2021-54

Preprint. Discussion started: 14 June 2021

importance of these regions for deep and intermediate water formation indicates that the redistribution of heat by changing ocean circulation is likely to continue increasing under anthropogenic warming - we find no indication of the ocean 'settling' into a new circulation state.

It is of particular interest that the (negative) redistributed heat inventory of the North Atlantic is proportional to the square of its excess heat inventory. Previous studies have found AMOC strength to be proportional to SST anomalies in the North Atlantic (Caesar et al., 2018). Assuming SST anomalies to be proportional to excess heat (?) would yield such a relationship between the excess and redistributed heat in the North Atlantic. From this, we infer that the redistribution of heat out of the North Atlantic in our simulation is proportional to both the AMOC strength and the temperature stratification in the North Atlantic.

Expressing the ratio of the redistributed to excess heat inventories in the Atlantic north of $26 \mathrm{~N}$ as a function of the time integrated AMOC volume transport anomaly at $26 \mathrm{~N}$ (climate change - control run), $\Delta \mathrm{Tr}$, we find that this ratio may be expressed as

$\frac{\mathcal{H}_{r}}{\mathcal{H}_{e}}=-0.0423+0.0005 \Delta \operatorname{Tr}$,

where $\mathcal{H}_{r}$ and $\mathcal{H}_{e}$ are the North Atlantic redistributed and excess heat inventories, respectively. We interpret this as the redistribution of heat southwards by an excess temperature field, even if AMOC strength were unchanged. This is counterintuitive, as the AMOC transports warm surface waters northward, and cool deep waters south: we might therefore expect an increase in northwards heat transport at constant AMOC strength. However, we find the imposition of an excess temperature field acts to redistribute the preindustrial temperature field downwards, redistributing heat downwards from the northward flowing waters to those moving south. The net result is that northward heat transport is reduced, and heat is redistributed out of the North Atlantic, without any change in the overturning circulation. Finally, we note that the increasing temperature stratification of the North Atlantic has the unexpected result of reducing the heat transport sensitivity at $26 \mathrm{~N}$ : we find a reduction of $0.014 \mathrm{PWSv}^{-1}$ from $0.075 \mathrm{PWSv}^{-1}$ in our control run to $0.061 \mathrm{PWSv}^{-1}$ in our climate change run. We also find an excess heat transport sensitivity of $-0.015 \mathrm{PWSv}^{-1}$ averaged over the period 1980-2099, approximately accounting for this difference.

Whilst it appears from this that the AMOC transports excess heat southwards, this is not the case. Instead, a strong correlation $\left(\mathrm{R}^{2}=0.68\right)$ is observed between the decline in AMOC strength and the increasing northward transport of excess heat. Thus, the reduction in northward heat transport due to a decrease in AMOC strength is compensated for by an increase in stratification, ameliorating the reduction in northwards heat transport due to the declining AMOC.

\subsection{Mapping storage of excess and redistributed temperature and salinity}

The regional patterns of decadal mean excess and redistributed temperature for the 2090s at four depth surfaces is shown in Figure 4, and the regional patterns of the decadal mean excess and redistributed salinity in Figure 5. For both temperature and everywhere, whilst excess salinity is generally positive in the South Atlantic, Subtropical North Atlantic and Indian Oceans, 
https://doi.org/10.5194/os-2021-54

Preprint. Discussion started: 14 June 2021

with the Pacific generally negative. This is consistent with increased evaporation over the Atlantic and increased atmospheric freshwater transport from the Atlantic to the Pacific.

It is generally expected that in a warming climate, the hydrological cycle will become amplified, with increased evaporation (precipitation) in regions of net evaporation (precipitation) (Durack and Wijffels, 2010), (Zika et al., 2018), (Gould and Cunningham, 2021). Thus, the salty regions of the ocean surface become saltier, and the fresh regions fresher. As these changes result from changing surface fluxes, this hydrological amplification should be captured by the excess salinity at the surface, rather than redistributed salinity.

This behaviour is visible in the Indian ocean and in the excess salinity peaks in the Subtropical North and South Atlantic, but is far exceeded by the pattern of increasing excess salinity in the Atlantic, and reduced excess salinity in the Pacific (Figure 5a). However, the pattern of change in excess salinity at the surface strongly resembles trends in Sea Surface Salinity found by Durack and Wijffels (2010) (Figure 5) over the period 1950-2008. We infer from this that historical trends in sea surface salinity are driven predominately by excess, rather than redistributed salinity: changes in evaporation and precipitation dominate over changes in circulation. This is in agreement with our inventory estimate from Figures 1 and 2, which indicate that changes to the hydrological cycle preceed those of significant warming, and that the scale of excess salinity generally exceeds that of redistributed salinity at all times. Patterns of surface excess salinity in the Atlantic also strongly resemble the patterns of salinity change in response to a $0.2 \mathrm{Wm}^{-2}$ per decade surface heat flux found by Zika et al. (2018).

The magnitude of redistributed temperature change in general decays slowly with depth: similar values are seen at the surface and $500 \mathrm{~m}$, as well as at 1000 and $2000 \mathrm{~m}$. In the Atlantic, at depths greater than $2100 \mathrm{~m}$, low latitude warming is dominated by redistributed, rather than excess temperature. In contrast, redistributed salinity change decays much more sharply with depth, with typical values approximately halving at each depth surface. Unlike temperature, at depth, the majority of salinity change is accounted for by the excess, rather than redistributed component, though appreciable changes are generally only found in the North Atlantic. However, some negative redistributed salinity is also found at depth in the North Atlantic, as well as some negative redistributed salinity at depth in the Southern Ocean.

The strong surface redistributed salinity signal in the Arctic appears to result from reduced sea ice freshwater transport from the marginal seas of the Arctic inwards. Previous studies using the NEMO GCM coupled to the LIM2 sea ice model have found that Arctic sea ice tends to grow along the coastal shelves of the Arctic Ocean, before being transported by the Beaufort Gyre circulation and transpolar drift (Moreau et al., 2016). The net result of this is to transport both freshwater and DIC from the coastal shelves to the centre of the Arctic Ocean: changes in this transport will therefore act to cause large and tightly correlated changes in DIC and salinity in the surface Arctic Ocean. Our decomposition therefore partitions salinity change resulting from changes in this transport to redistribution. Similar changes in sea ice transport also act to cause redistributed freshening in the coastal Southern Ocean.

The total inventory change in heat, salt, and density by the last decade of our simulation, as well as the storage of the excess and redistributed components are shown in Figure 6, for the upper 2000m of the ocean. We present these as contributions to steric sea level change, allowing for both normalisation and a comparison of contributions to steric sea level rise. Inventories in native units are also presented in Figure 7. As with contributions to steric sea level rise, these are the 2090's decadal mean of 


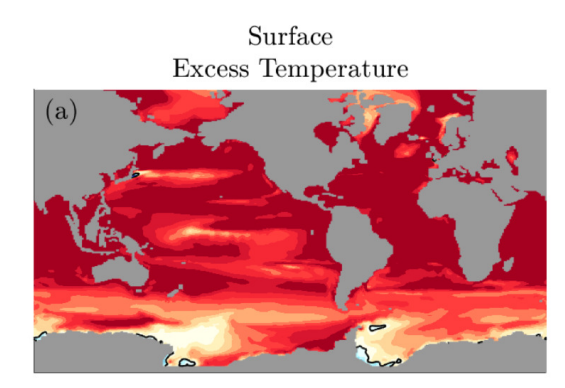

$\Delta \Theta_{e}$ at $503 \mathrm{~m}$
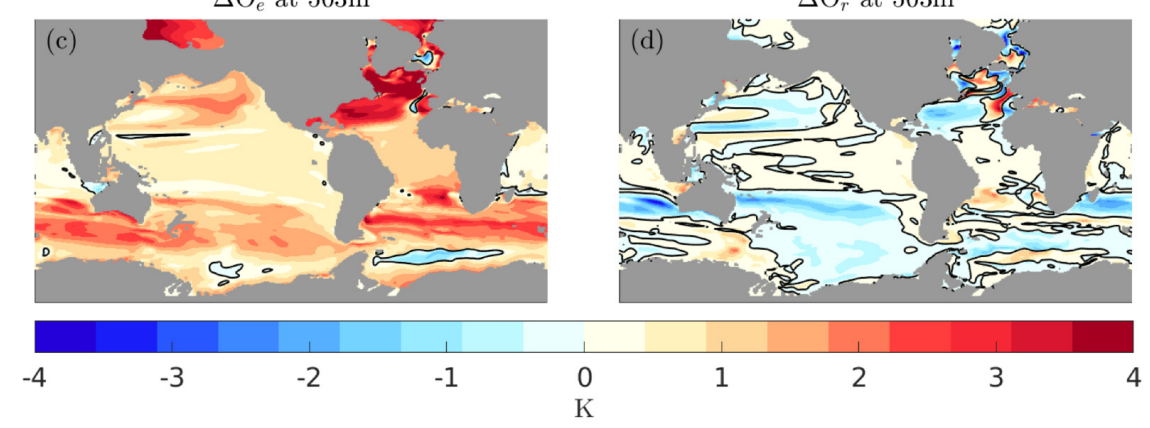

$\Delta \Theta_{e}$ at $1041 \mathrm{~m}$

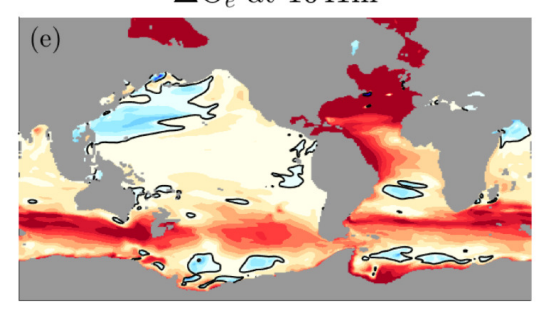

$\Delta \Theta_{e}$ at $2097 \mathrm{~m}$
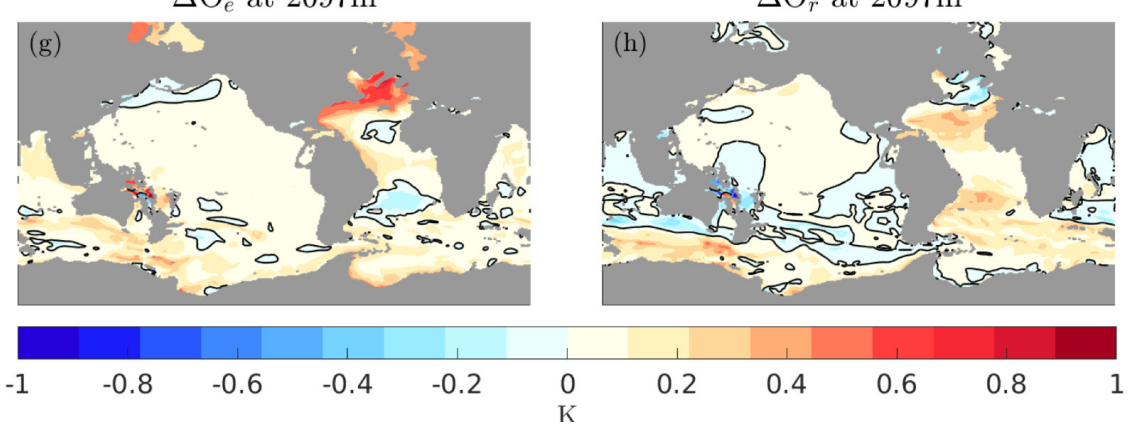

Redistributed Temperature

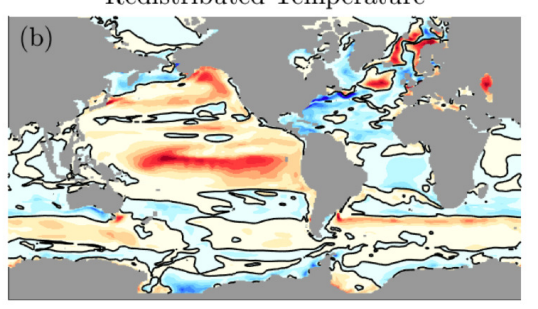

$\Delta \Theta_{r}$ at $503 \mathrm{~m}$

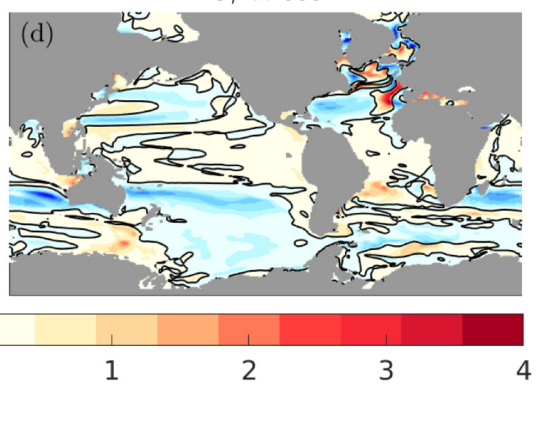

$\Delta \Theta_{r}$ at $1041 \mathrm{~m}$

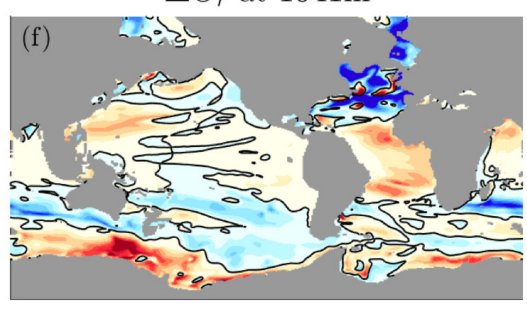

$\Delta \Theta_{r}$ at $2097 \mathrm{~m}$

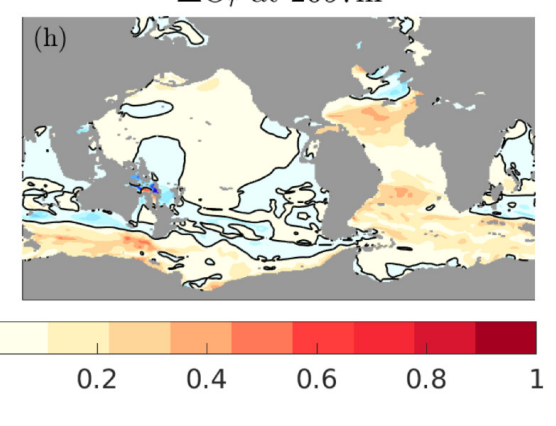

Figure 4. Maps of excess and redistributed temperature on four depth surfaces: the surface, 503m, 1041m and 2097m. Values given are the decadal mean for the decade 2090-2099. The zero contour is shown in black, with panels (a)-(d) and (e)-(h) shading colour axes.

each quantity for the upper 2000m. Zero contours are shown in black. On this timescale, excess (Figure 6c, 7b) and total (Figure 7a) heat inventory changes are positive nearly everywhere, with the exception of the Weddell and Ross gyres. Redistributed 


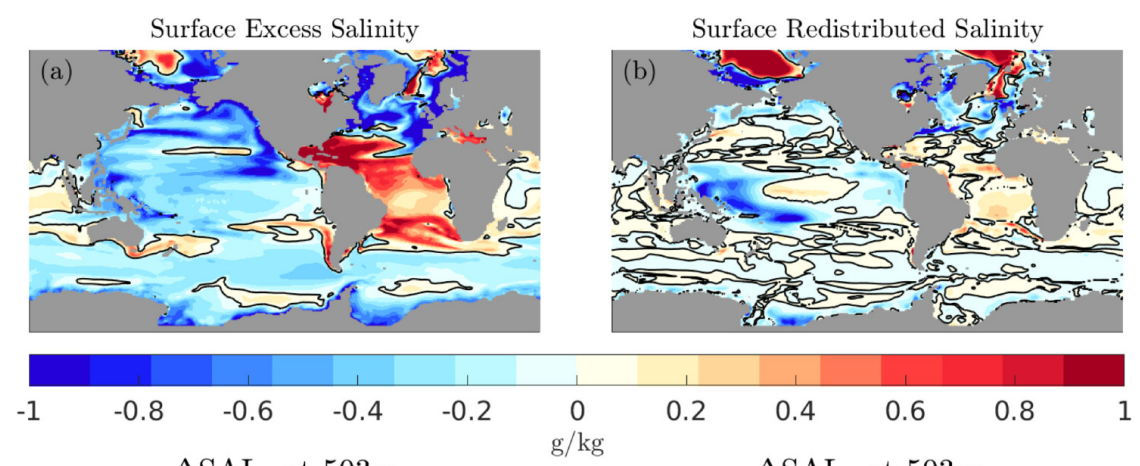

$\Delta \mathrm{SAL}_{e}$ at $503 \mathrm{~m}$

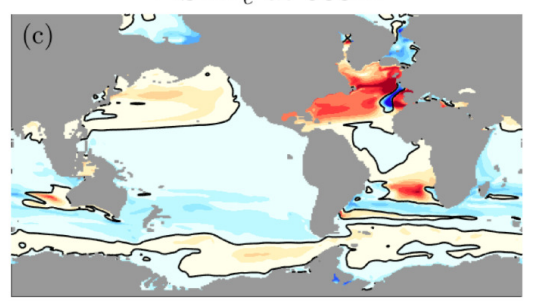

$\triangle \mathrm{SAL}_{r}$ at $503 \mathrm{~m}$

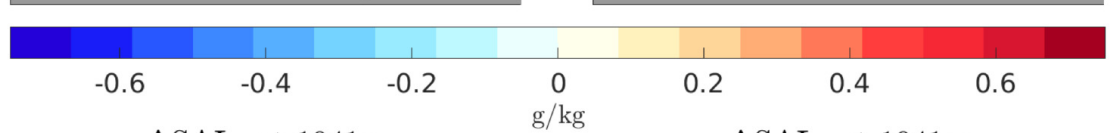

$\Delta \mathrm{SAL}_{e}$ at $1041 \mathrm{~m}$

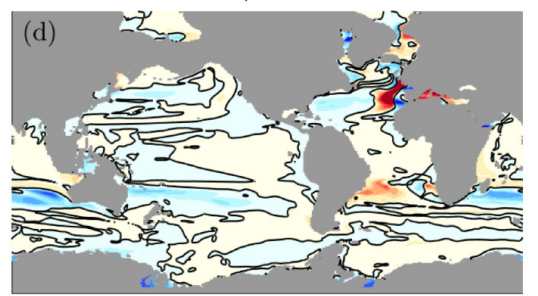

$\Delta \mathrm{SAL}_{r}$ at $1041 \mathrm{~m}$
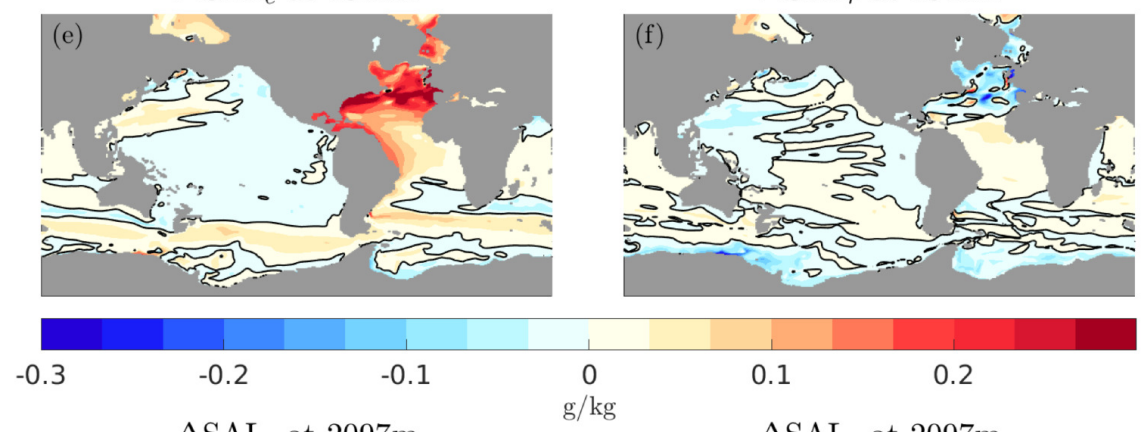

$\Delta \mathrm{SAL}_{e}$ at $2097 \mathrm{~m}$

$\triangle \mathrm{SAL}_{r}$ at $2097 \mathrm{~m}$

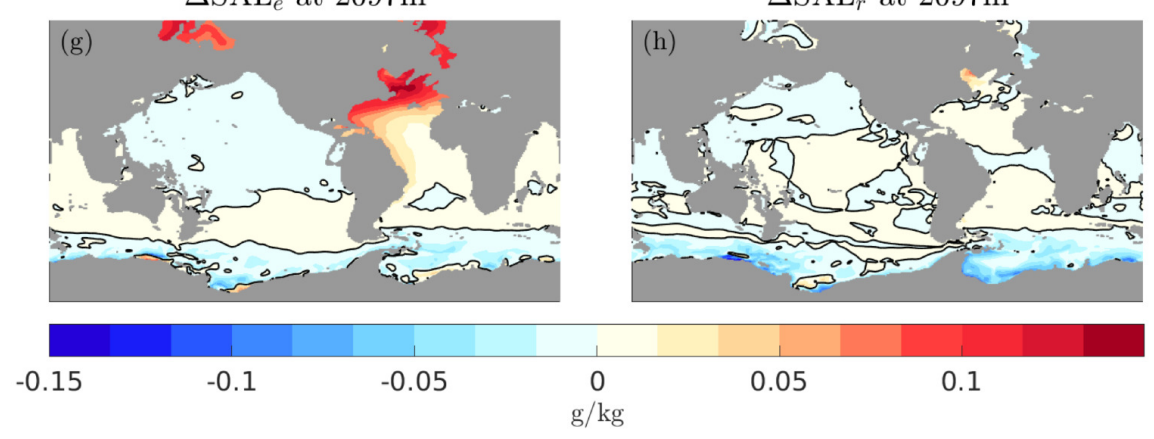

Figure 5. Maps of excess and redistributed temperature on four depth surfaces: the surface, 503m, 1041m and 2097m. Values given are the decadal mean for the decade 2090-2099. The zero contour is shown in black, with panels (a)-(d) and (e)-(h) shading colour axes. 
https://doi.org/10.5194/os-2021-54

Preprint. Discussion started: 14 June 2021

heat inventories are negative generally in the North Atlantic (Figure 6f, 7c), with the largest values seen in the Labrador and Norwegian seas. In the Pacific and Indian Oceans, redistributed heat inventories are negative generally in the South, possibly reflecting a shift in the position of the Antarctic Circumpolar Current. Though over a different period and enforcing different assumptions, our patterns of heat redistribution are qualitatively similar to those of Bronselaer and Zanna (2020) (Figure 4), indicating both methods perform similarly.

Salinity inventory changes show a very different geographical distribution: here, excess salinity increases uniformly only in the Atlantic and Arctic oceans (Figure 6e, 7e). Total salinity change is again dominated by the excess here. As with heat, the signature of AMOC slowdown can be seen in the redistributed salinity signal: we observe redistribution driven cooling and freshening in the North Atlantic and redistribution driven warming and salinification in the Equatorial and South Atlantic. This redistribution driven cooling and freshening acts to oppose the warming and salinification associated with increased surface heating and concurrent increases in Evaporation - Precipitation.

Density inventory changes are relatively globally uniform (Figure $6 \mathrm{a}, 7 \mathrm{~g}$ ): a decrease is seen in the total change and excess inventory nearly everywhere, with the exception of the Weddell and Ross seas, as well as the central Arctic Ocean. The Arctic Ocean decrease is dominated by the changes in freshwater transport, whereas the Weddell and Ross sea decrease result from upwelling cool water. In the Atlantic, large changes in steric sea level resulting from excess temperature are significantly reduced by the accumulation of excess salinity, and a similar cancellation is seen in the redistributed components.

\section{Discussion and Conclusions}

We have demonstrated a new technique for estimating the redistribution of heat and salinity by the ocean in response to anthropogenic climate change, allowing us to identify the excess signal and producing estimates consistent with other reconstructions. A key strength of this technique is that it also allows us to estimate not only the redistribution of heat, but also salinity, and is in principle extensible to other tracer distributions that evolve in response to anthropogenic climate change. Furthermore, its implementation is such that in order to decompose the change in a tracer, we require only high frequency timeseries of the tracer in question, and a tracer which we may assume to change distribution only through redistribution: $\mathrm{C}_{\text {nat }}$ is a particularly useful tracer to this end.

Our globally integrated estimates indicate that the excess and redistributed temperature signals are currently of a similar size (Figure 1), with excess temperature signals expected to exceed the redistributed temperature signals towards the end of the 2020's. This is in keeping with previous studies which find excess heat beginning to dominate over redistributed heat in the period 2011-2060 (Bronselaer and Zanna, 2020). Of course, as we utilise only one climate change run from a single model, there is a large uncertainty associated with this.

We have also produced, to our knowledge, the first modelled estimates of the redistribution of the preindustrial salinity field by the ocean and so the excess salinity field: that is, the changes in salinity due to changes in the balance of evaporation and precipitation, rather than ocean transport. By extension, we have also been able to produce the first estimates of excess and redistributed density. Curiously, we find that the penetration to depth of the excess redistributed salinity and density signals are 
https://doi.org/10.5194/os-2021-54

Preprint. Discussion started: 14 June 2021

(c) Author(s) 2021. CC BY 4.0 License.

Total Steric Sea Level Rise

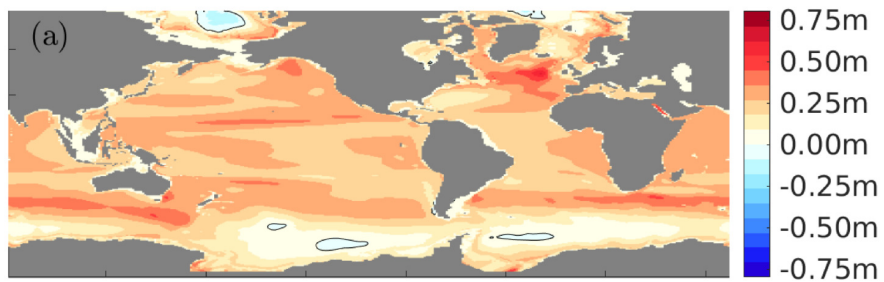

Redistributed Steric Sea Level Rise

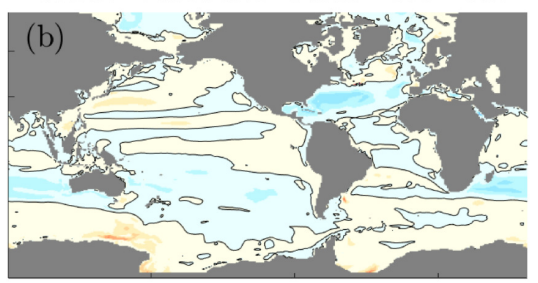

Redistibuted Halosteric Sea Level Rise

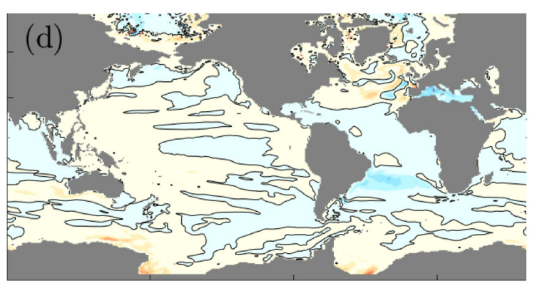

Redistributed Thermosteric Sea Level Rise

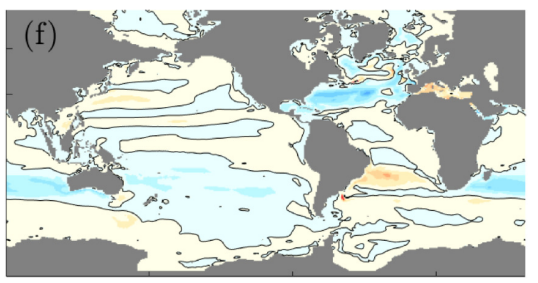

Excess Steric Sea Level Rise

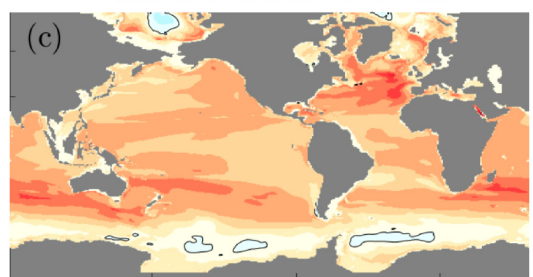

Excess Halosteric Sea Level Rise

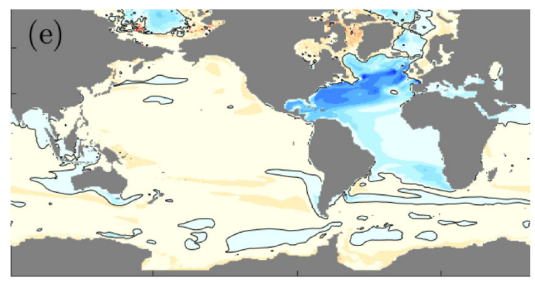

Excess Thermosteric Sea Level Rise

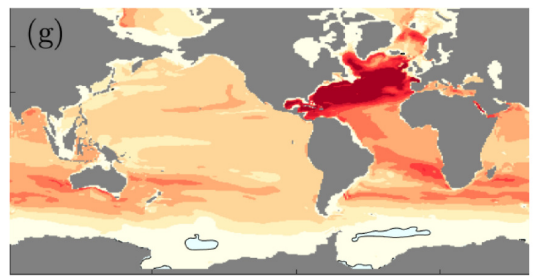

Figure 6. 2090's mean steric, halosteric and thermosteric contributions to sea level rise, as well as the total. Only contributions from the upper $2000 \mathrm{~m}$ are given. These can therefore also be analogously thought of as the upper $2000 \mathrm{~m}$ inventories of the decomposed heat and salinity change.

far weaker than that of temperature, which, particularly in the Atlantic, accounts for the majority of deep warming. However, we do find several signals in surface excess and redistributed salinity changes consistent with hydrological amplification, as well as a salinity signal in the South Atlantic as a previously identified 'salinity pile up' in the South Atlantic consistent with AMOC slowdown (Zhu and Liu, 2020). By the 2090's, the Southern and Subtropical North Atlantic show increasing redistributed surface salinity as a result of AMOC slowdown, with a decreasing redistributed salinity in the Subpolar North Atlantic. At 


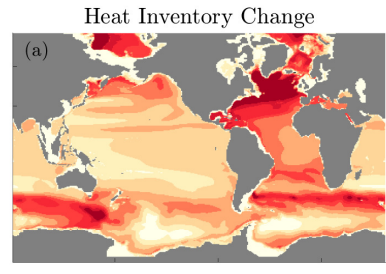

Salinity Inventory Change

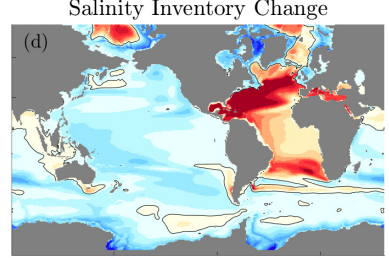

Density Inventory Change

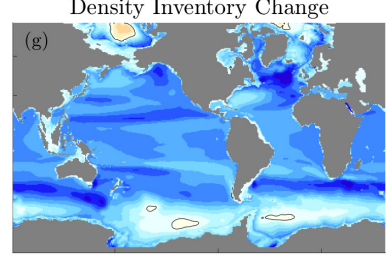

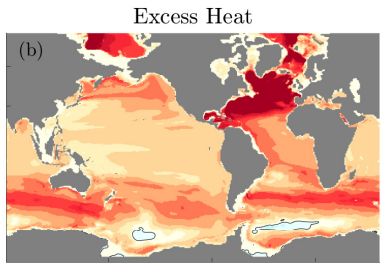

Excess Salinity

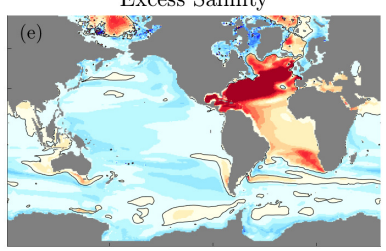

Excess Density

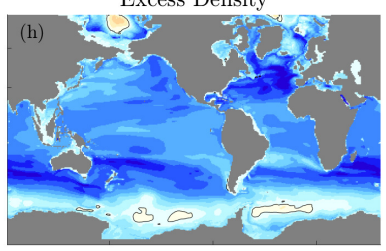

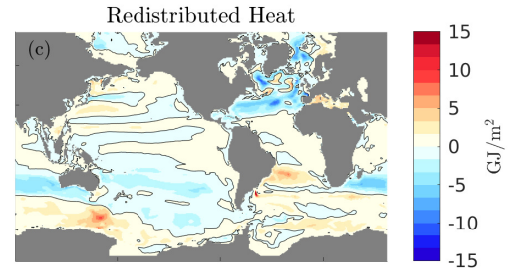
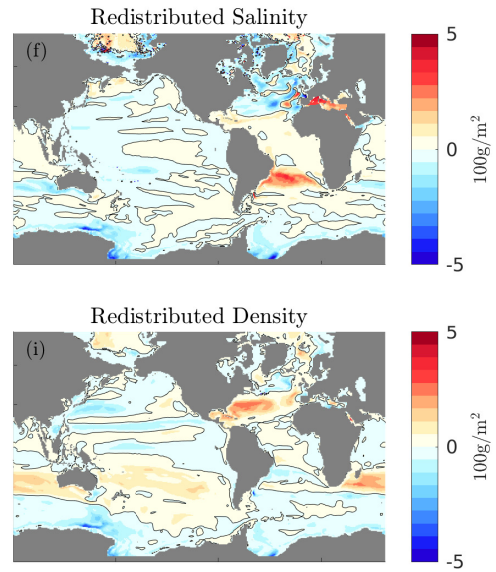

Figure 7. The total, excess, and redistributed heat, salinity and density inventories presented as column inventories for the upper $2000 \mathrm{~m}$ of the ocean. These quantities are calculated as the decadal mean anomalies of the 2090's relative to preindustrial. Scales are shared for each quantity.

the surface, we find that the majority of salinity change results from changes in E-P (excess), rather than circulation changes (redistributed), and that these patterns in excess salinity are consistent with both historical observations globally (Durack and Wijffels, 2010), and, in the Atlantic, with the salinity response to an idealised surface heat flux (Zika et al., 2018). We also find that the decrease in global mean excess salinity occurs earlier than the increase in globally integrated excess heat, consistent with previous studies which find significant ice sheet loss even in the early $20^{\text {th }}$ century, before appreciable global warming (Kjeldsen et al., 2015). These results suggest that whilst historical observations of temperature changes are dominated by redistribution, with the excess temperature only likely to dominate in the coming decades, historical changes in salinity may in fact be predominately the result of excess salinity, rather than redistribution.

In applying our technique to the Atlantic, we have shown explicitly the redistribution of heat associated with changes to the overturning circulation, in addition to the aforementioned salinity signal. We also find fingerprints of AMOC change in both the redistributed temperature and salinity inventories of the North and South Atlantic: a large and rapid accumulation of negative excess heat in the North Atlantic over the period 2037-2099, as well as the accumulation of a large inventory of redistributed 
https://doi.org/10.5194/os-2021-54

Preprint. Discussion started: 14 June 2021

salinity in the South Atlantic over the same period. We suggest that the application of this technique to historical observations may therefore help to constrain estimates of historical AMOC strength.

Whilst by the end of the $21^{\text {st }}$ century temperature changes are expected to be dominated by excess temperature, it is less clear for salinity that this will be the case: with the exception of a large increase in excess salinity in the Atlantic, excess salinity estimates are largely uniform, and the contributions of redistributed and excess salinity to halosteric SLR are of similar scales in most locations (Figure (6)): despite the indications that patterns of regional change in salinity appear to be dominated by the excess component, both historically and by the end of the $21^{\text {st }}$ century. Though changes in salinity under anthropogenic climate change are expected to be less drastic than temperature, decomposing salinity into excess and redistributed components is also crucial to understanding the response of the ocean to global warming, due to its role in thermohaline circulation.

The decomposition of salinity also allows us to directly examine the dynamical forcing of excess and redistributed temperature and salinity. By combining our estimates of excess temperature and salinity, we can directly compute the excess density change, and the redistribution of density. In the North Atlantic, we find warming and salinification in the excess components, and cooling and freshing in the redistributed components. In both cases, these changes are in a density compensating fashion. Previous studies have noted that whilst density compensated water mass changes may be a general property of the ocean, the behaviour is particularly marked in the Atlantic (Lowe and Gregory, 2006), as well as important for contemporary Atlantic deep ocean heat uptake (Mauritzen et al., 2012), though it is uncertain how this will evolve. Our results suggest that approximately density compensated changes in excess temperature and salinity remain important by the 2090's, though excess density generally acts to increase stratification: (negative) excess density generally decays quickly with depth. A consequence of this is that changes in surface freshwater fluxes associated with climate change oppose the reduction of overturning circulation associated with increased surface warming, increasing the North Atlantic's capacity to sequester excess heat. This suggests that the excess contribution to steric SLR in the Atlantic will continue to grow on the longest timescales. However, the much smaller redistributed contribution to density indicates that changes to ocean circulation will have little effect on steric SLR in the North Atlantic, and perhaps even act to ameliorate steric SLR. Finally, redistributed density compensation in the North Atlantic begins to break down in approximately 2050 (Figure 2 (f)), as the redistribution of heat out of the North Atlantic significantly exceeds that of salinity.

Globally, we find redistributed density inventories with scales approximately half the excess density inventory at most locations globally (Figure 6). As a result, the redistributed temperature and salinity fields have an associated effect on dynamics: the redistributed fields are dynamically active. Better understanding the feedback of redistributed fields on dynamics may therefore prove a useful tool in understanding timescales for future ocean circulation change associated with anthropogenic climate change.

Finally, although only being applied within a single model, our patterns of excess and redistributed heat storage are consistent with previous studies (Bronselaer and Zanna, 2020), (Winton et al., 2013), (Banks and Gregory, 2006) despite differing assumptions used in the calculation of the redistribution of heat from carbon. We have also shown that this technique can be considered, in the case of temperature, to be the opposite limit of a generalised relationship between temperature and carbon change used in previous studies. A key benefit of the method introduced here is that it can be used to estimate the redistribution 
https://doi.org/10.5194/os-2021-54

Preprint. Discussion started: 14 June 2021

of a suite of tracers as it relies only on spatial information, and it does not necessarily require estimates of global mean quantities. In combination with other techniques, we believe this method to be a powerful tool for understanding the mechanistic drivers of changes to future ocean temperature, salinity and density change. Though particularly useful for understanding future sea level rise, it may also have important uses for understanding the future transport of salinity and carbon by sea ice(Moreau et al., 2016), sequestration of carbon by the ocean (Frölicher et al., 2015) and northwards heat transport of the Atlantic (Lowe and Gregory, 2006),(Mauritzen et al., 2012).

Code and data availability. The model output we use as well as the code used to decompose the temperature and salinity fields are available upon request. Core functionality for the decomposition is freely available at https://github.com/charles-turner-1/temp_decomp.

\section{Appendix A: Uncertainty in estimates of local redistribution}

We estimate a local gradient gradient, $\Delta \Theta / \Delta \mathrm{C}_{\text {nat }}$ or $\Delta S / \Delta \mathrm{C}_{\text {nat }}$ by applying PCA to the raw data: timeseries of the two variables at a point. We choose this indirect statistical approach as it is applicable to both models and observations.

We then scale the data to normalise the ranges of $\Theta / S$ and $\mathrm{C}_{\text {nat }}$ before again performing PCA to estimate the fraction of the covariance contained within each principle component. This yields the fraction of the total variance explained by each principal component, which we refer to as $\varepsilon_{1}$ and $\varepsilon_{2}$ : these can be thought of the axes of an ellipse describing our scatter cloud. A fit which is a perfect line can be thought of as the limit of this ellipse where $\varepsilon_{1} \rightarrow 1$ and $\varepsilon_{2} \rightarrow 0$. Conversely, an essentially random fit through a spherical cloud of points can be thought of as the case where $\varepsilon_{1}=\varepsilon_{2}$.

We use the eccentricity of this ellipse as a suppression factor, $S_{u}$ :

$S_{u}=\sqrt{1-\left(\frac{\varepsilon_{2}}{\varepsilon_{1}}\right)^{2}}$

The need for conservative estimates of confidence in the fit is particularly important for fits in which no discernable correlation can be drawn: for these, gradients associating minor changes in $\mathrm{C}_{\text {nat }}$ with large changes in $\Theta$ or $S$ can be obtained, effectively at random, and so our suppression factor must remove these effectively. As we concern ourselves primarily with inventories, this approach was found to be preferable to including large uncertainties due to a small number of spurious points, or simply setting a threshold below which we do not attempt to diagnose the redistribution of heat. Only $6 \%$ of $\varepsilon_{1}$ values are scaled by a factor of $1 / 2$ or less: this was found to be a suitable compromise, with only the most unreliable estimates strongly suppressed.

Approximately $80 \%$ of grid cells globally have an eccentricity of $0.8-1$, and we find by the end of our run, the suppression factor alters the redistributed temperature of $93 \%$ grid cells globally by less than 0.04 degrees, and $60 \%$ by less than 0.02 degrees, though the RMS mean redistributed temperature is reduced by $5 \%$. However, the small number of grid cells producing extremely large estimates (10's of degrees of change) are effectively suppressed. We therefore estimate that the statistical nature of our method introduces an error of approximately 5\% into our inventories. Alternative methods may produce better quantifications of uncertainty, though are not considered here as the eccentricity method was sufficient for our purposes. 
We then calculate the redistribution coefficient $\kappa_{r}$ as

The implementation of this is demonstrated in Figure A1, for two points in the North Atlantic at approximately 24 North, 30W and $850 \mathrm{~m}$ and $1950 \mathrm{~m}$. The poorly correlated point, Figure A1a and A1c, is an extreme outlier, shown for demonstrative purposes. Here the fit is essentially random, and so estimates of temperature redistribution are scaled to reflect this uncertainty: the eccentricity of the ellipse described by the cloud of points in $\Theta-C_{\text {nat }}$ space is used as a scale factor. For a strongly correlated point, shown in panels (b) and (d), temperature and $\mathrm{C}_{\text {nat }}$ variability are almost perfectly anticorrelated, representing the dominance of vertical heave and shoal in determining the redistribution coefficient $\kappa_{r}$. Here, $\kappa_{r}=-0.0210, \partial_{z} \Theta / \partial_{z} \mathrm{DIC}=$ -0.0208. The strongly correlated point also demonstrates how our parallel velocities restraint is greatly relaxed in practice: horizontal gradients at this location are small (or they would contribute to $\kappa_{r}$ ), and so horizontal circulatory changes will not contribute strongly to temperature redistribution, even if our condition on parallel velocities $\left(\mathbf{v}_{s} \| \mathbf{v}_{l}\right)$ is not well satisfied. In Figure A1, the technique is demonstrated using monthly mean data for visibility, though we use yearly mean data when producing our estimates.

\section{Appendix B: Merging one and two step estimates}

Our estimation technique assumes that the relationship between short timescale changes is dominated by circulation variability. However, at the surface, changes in salinity and $\mathrm{C}_{\text {nat }}$ are instead dominated by freshwater fluxes: an excess of evaporation over precipitation will increase concentrations of salt and $\mathrm{C}_{\text {nat }}$, coupling changes in the two. This leads to changes which are properly described as excess salinity being partitioned into redistributed salinity.

To account for this, we use a two step estimation process. Equation 15 states that we may estimate the redistribution in an arbitrary tracer $Q$, provided that $\mathrm{C}_{\text {nat }}$ changes only due to redistribution:

$\frac{d Q_{r}}{d \mathrm{C}_{\text {nat }}}=\frac{\mathbf{v}_{l} \cdot \nabla Q}{\mathbf{v}_{l} \cdot \nabla \mathrm{C}_{\text {nat }}}$

440 However, estimations of this nature are not limited simply to $\mathrm{C}_{\text {nat }}$ : we may use any tracer which changes only through redistribution. We utilise this by using temperature redistribution in the upper $200 \mathrm{~m}$ to estimate salinity redistribution. The same approach is applied not to the $\Theta-\mathrm{C}_{\text {nat }}$ or $S-\mathrm{C}_{\text {nat }}$ curve, but the T-S curve, and the redistributed salinity is then estimated from this:

$\Delta S_{r}=\frac{\mathbf{v} \cdot \nabla S}{\mathbf{v} \cdot \nabla \Theta} \Delta \Theta_{r}$

We then merge the two estimates using a sigmoidal weighting scheme based on depth. Our simulations use 64 vertical levels, with the 20th level corresponding to approximately $200 \mathrm{~m}$. Denoting the $\mathrm{i}^{\text {th }}$ vertical level $z_{i}$, the one step estimate as $S_{1}$ and the two step estimate as $S_{2}$, we calculate our final estimate of salinity redistribution, $S$, as

$S=S_{1} \times \sigma\left(\frac{z_{i}+20}{2}\right)+S_{2} \times\left(1-\sigma\left(\frac{z_{i}+20}{2}\right)\right)$, 
https://doi.org/10.5194/os-2021-54

Preprint. Discussion started: 14 June 2021

(c) Author(s) 2021. CC BY 4.0 License.

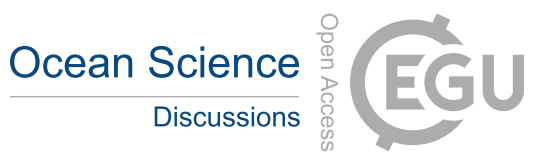

(c) (i)

where $\sigma(z)$ is the sigmoid function:

$450 \sigma(z)=\frac{1}{1+e^{-z}}$

Author contributions. CT designed the technique for temperature decomposition, and EM realised the extensibility to salinity. All authors contributed to interpretation and writing the manuscript.

Competing interests. The authors declare no competing interests

Acknowledgements. We would like to thank Matthew Couldrey for kindly allowing us to use his simulations for this research. EM, PB were supported by Natural Environment Research Council grant NE/P019293/1 (TICTOC) CT was supported by the Natural Environmental Research Council [grant number NE/L002531/1] 
https://doi.org/10.5194/os-2021-54

Preprint. Discussion started: 14 June 2021

\section{References}

Banks, H. T. and Gregory, J. M.: Mechanisms of ocean heat uptake in a coupled climate model and the implications for tracer based predictions of ocean heat uptake, Geophysical Research Letters, 33, https://doi.org/https://doi.org/10.1029/2005GL025352, 2006.

Bindoff, N. L. and Mcdougall, T. J.: Diagnosing Climate Change and Ocean Ventilation Using Hydrographic Data, Journal of Physical Oceanography, 24, 1137 - 1152, https://doi.org/10.1175/1520-0485(1994)024<1137:DCCAOV>2.0.CO;2, 1994.

Bronselaer, B. and Zanna, L.: Heat and carbon coupling reveals ocean warming due to circulation changes, Nature, 584, 227-233, https://doi.org/10.1038/s41586-020-2573-5, 2020.

Caesar, L., Rahmstorf, S., Robinson, A., Feulner, G., and Saba, V.: Observed fingerprint of a weakening Atlantic Ocean overturning circulation, Nature, 556, 191-196, https://doi.org/10.1038/s41586-018-0006-5, 2018.

Church, J., Clark, P., Cazenave, A., Gregory, J., Jevrejeva, S., Levermann, A., Merrifield, M., Milne, G., Nerem, R., Nunn, P., Payne, A., Pfeffer, W., Stammer, D., and Unnikrishnan, A.: Sea Level Change, in: Climate Change 2013: The Physical Science Basis. Contribution of Working Group I to the Fifth Assessment Report of the Intergovernmental Panel on Climate Change, edited by Stocker, T., Qin, D., Plattner, G.-K., Tignor, M., Allen, S., Boschung, J., Nauels, A., Xia, Y., Bex, V., and Midgley, P., pp. 1137-1216, Cambridge University Press, https://doi.org/10.1017/CBO9781107415324.026, section: 13 Type: Book Section, 2013.

Church, J. A., White, N. J., Konikow, L. F., Domingues, C. M., Cogley, J. G., Rignot, E., Gregory, J. M., van den Broeke, M. R., Monaghan, A. J., and Velicogna, I.: Revisiting the Earth's sea-level and energy budgets from 1961 to 2008, Geophysical Research Letters, 38, https://doi.org/https://doi.org/10.1029/2011GL048794, 2011.

Collins, W. J., Bellouin, N., Doutriaux-Boucher, M., Gedney, N., Halloran, P., Hinton, T., Hughes, J., Jones, C. D., Joshi, M., Liddicoat, S., Martin, G., O'Connor, F., Rae, J., Senior, C., Sitch, S., Totterdell, I., Wiltshire, A., and Woodward, S.: Development and evaluation of an Earth-System model - HadGEM2, Geoscientific Model Development, 4, 1051-1075, https://doi.org/10.5194/gmd-4-1051-2011, 2011.

Couldrey, M. P., Oliver, K. I. C., Yool, A., Halloran, P. R., and Achterberg, E. P.: Drivers of $21^{\text {st }}$ Century carbon cycle variability in the North Atlantic Ocean, Biogeosciences Discussions, 2019, 1-33, https://doi.org/10.5194/bg-2019-16, 2019.

Desbruyères, D., McDonagh, E. L., King, B. A., and Thierry, V.: Global and Full-Depth Ocean Temperature Trends during the Early TwentyFirst Century from Argo and Repeat Hydrography, Journal of Climate, 30, 1985 - 1997, https://doi.org/10.1175/JCLI-D-16-0396.1, 2017.

Durack, P. J. and Wijffels, S. E.: Fifty-Year Trends in Global Ocean Salinities and Their Relationship to Broad-Scale Warming, Journal of Climate, 23, 4342 - 4362, https://doi.org/10.1175/2010JCLI3377.1, 2010.

Frölicher, T. L., Sarmiento, J. L., Paynter, D. J., Dunne, J. P., Krasting, J. P., and Winton, M.: Dominance of the Southern Ocean in Anthropogenic Carbon and Heat Uptake in CMIP5 Models, Journal of Climate, 28, 862 - 886, https://doi.org/10.1175/JCLI-D-14-00117.1, 2015.

Goodwin, P., Williams, R. G., and Ridgwell, A.: Sensitivity of climate to cumulative carbon emissions due to compensation of ocean heat and carbon uptake, Nature Geoscience, 8, 29-34, https://doi.org/10.1038/ngeo2304, 2015.

Gould, W. J. and Cunningham, S. A.: Global-scale patterns of observed sea surface salinity intensified since the 1870 s, Communications Earth \& Environment, 2, 76, https://doi.org/10.1038/s43247-021-00161-3, 2021.

490 Gruber, N., Sarmiento, J. L., and Stocker, T. F.: An improved method for detecting anthropogenic CO2 in the oceans, Global Biogeochemical Cycles, 10, 809-837, https://doi.org/https://doi.org/10.1029/96GB01608, 1996.

Hall, T. M., Haine, T. W. N., and Waugh, D. W.: Inferring the concentration of anthropogenic carbon in the ocean from tracers, Global Biogeochemical Cycles, 16, 78-1-78-15, https://doi.org/https://doi.org/10.1029/2001GB001835, 2002. 
https://doi.org/10.5194/os-2021-54

Preprint. Discussion started: 14 June 2021

Hinkel, J., Lincke, D., Vafeidis, A. T., Perrette, M., Nicholls, R. J., Tol, R. S. J., Marzeion, B., Fettweis, X., Ionescu, C., and Levermann,

A.: Coastal flood damage and adaptation costs under 21st century sea-level rise, Proceedings of the National Academy of Sciences, 111 , 3292-3297, https://doi.org/10.1073/pnas.1222469111, 2014.

Khatiwala, S., Visbeck, M., and Cane, M. A.: Accelerated simulation of passive tracers in ocean circulation models, Ocean Modelling, 9 , 51-69, https://doi.org/https://doi.org/10.1016/j.ocemod.2004.04.002, 2005.

Khatiwala, S., Tanhua, T., Mikaloff Fletcher, S., Gerber, M., Doney, S. C., Graven, H. D., Gruber, N., McKinley, G. A., Murata, A., Ríos, A. F., and Sabine, C. L.: Global ocean storage of anthropogenic carbon, Biogeosciences, 10, 2169-2191, https://doi.org/10.5194/bg-102169-2013, 2013.

Kjeldsen, K., Korsgaard, N., Bjørk, A., Khan, S., Box, J., Funder, S., Larsen, N., Bamber, J., Colgan, W., van den Broeke, M., SiggaardAndersen, M.-L., Nuth, C., Schomacker, A., Andresen, C., Willerslev, E., and Kjær, K.: Spatial and temporal distribution of mass loss from the Greenland Ice Sheet since AD 1900, Nature, 528, 396-400, https://doi.org/10.1038/nature16183, 2015.

Lowe, J. A. and Gregory, J. M.: Understanding projections of sea level rise in a Hadley Centre coupled climate model, Journal of Geophysical Research: Oceans, 111, https://doi.org/https://doi.org/10.1029/2005JC003421, 2006.

Mauritzen, C., Melsom, A., and Sutton, R. T.: Importance of density-compensated temperature change for deep North Atlantic Ocean heat uptake, Nature Geoscience, 5, 905-910, https://doi.org/10.1038/ngeo1639, 2012.

McDougall, T. J. and Barker, P. M.: Getting started with TEOS-10 and the Gibbs Seawater (GSW) Oceanographic Toolbox, SCOR/IAPSO WG127, p. 28, 2011.

Moreau, S., Vancoppenolle, M., Bopp, L., Aumont, O., Madec, G., Delille, B., Tison, J.-L., Barriat, P.-Y., and Goosse, H.: Assessment of the sea-ice carbon pump: Insights from a three-dimensional ocean-sea-ice biogeochemical model (NEMO-LIM-PISCES), Elementa: Science of the Anthropocene, 4, https://doi.org/10.12952/journal.elementa.000122, 000122, 2016.

Pardaens, A. K., Lowe, J. A., Brown, S., Nicholls, R. J., and de Gusmão, D.: Sea-level rise and impacts projections under a future scenario with large greenhouse gas emission reductions, Geophysical Research Letters, 38, https://doi.org/https://doi.org/10.1029/2011GL047678, 2011.

Timmermann, R., Goosse, H., Madec, G., Fichefet, T., Ethe, C., and Dulière, V.: On the representation of high latitude processes in the ORCA-LIM global coupled sea ice-ocean model, Ocean Modelling, 8, 175-201, 2005.

Touratier, F. and Goyet, C.: Definition, properties, and Atlantic Ocean distribution of the new tracer TrOCA, Journal of Marine Systems, 46, 169-179, https://doi.org/https://doi.org/10.1016/j.jmarsys.2003.11.016, 2004.

Vázquez-Rodríguez, M., Padin, X. A., Ríos, A. F., Bellerby, R. G. J., and Pérez, F. F.: An upgraded carbon-based method to estimate the anthropogenic fraction of dissolved $\mathrm{CO}_{2}$ in the Atlantic Ocean, Biogeosciences Discussions, 6, 4527-4571, https://doi.org/10.5194/bgd6-4527-2009, 2009.

Winton, M., Griffies, S. M., Samuels, B. L., Sarmiento, J. L., and Frölicher, T. L.: Connecting Changing Ocean Circulation with Changing Climate, Journal of Climate, 26, 2268 - 2278, https://doi.org/10.1175/JCLI-D-12-00296.1, 2013.

Yool, A., Popova, E. E., and Anderson, T. R.: MEDUSA-2.0: an intermediate complexity biogeochemical model of the marine carbon cycle for climate change and ocean acidification studies, Geoscientific Model Development, 6, 1767-1811, https://doi.org/10.5194/gmd-6-1767$2013,2013$.

Zhu, C. and Liu, Z.: Weakening Atlantic overturning circulation causes South Atlantic salinity pile-up, Nature Climate Change, 10, 9981003, https://doi.org/10.1038/s41558-020-0897-7, 2020. 
https://doi.org/10.5194/os-2021-54

Preprint. Discussion started: 14 June 2021

(C) Author(s) 2021. CC BY 4.0 License.

Ocean Science

Discussions

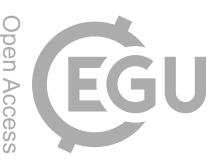
(c) (i)

Zika, J. D., Skliris, N., Blaker, A. T., Marsh, R., Nurser, A. J. G., and Josey, S. A.: Improved estimates of water cycle change from ocean salinity: the key role of ocean warming, Environmental Research Letters, 13, 074 036, https://doi.org/10.1088/1748-9326/aace42, 2018.

Zika, J. D., Gregory, J. M., McDonagh, E. L., Marzocchi, A., and Clément, L.: Recent Water Mass Changes Reveal Mechanisms of Ocean Warming, Journal of Climate, 34, 3461 - 3479, https://doi.org/10.1175/JCLI-D-20-0355.1, 2021. 

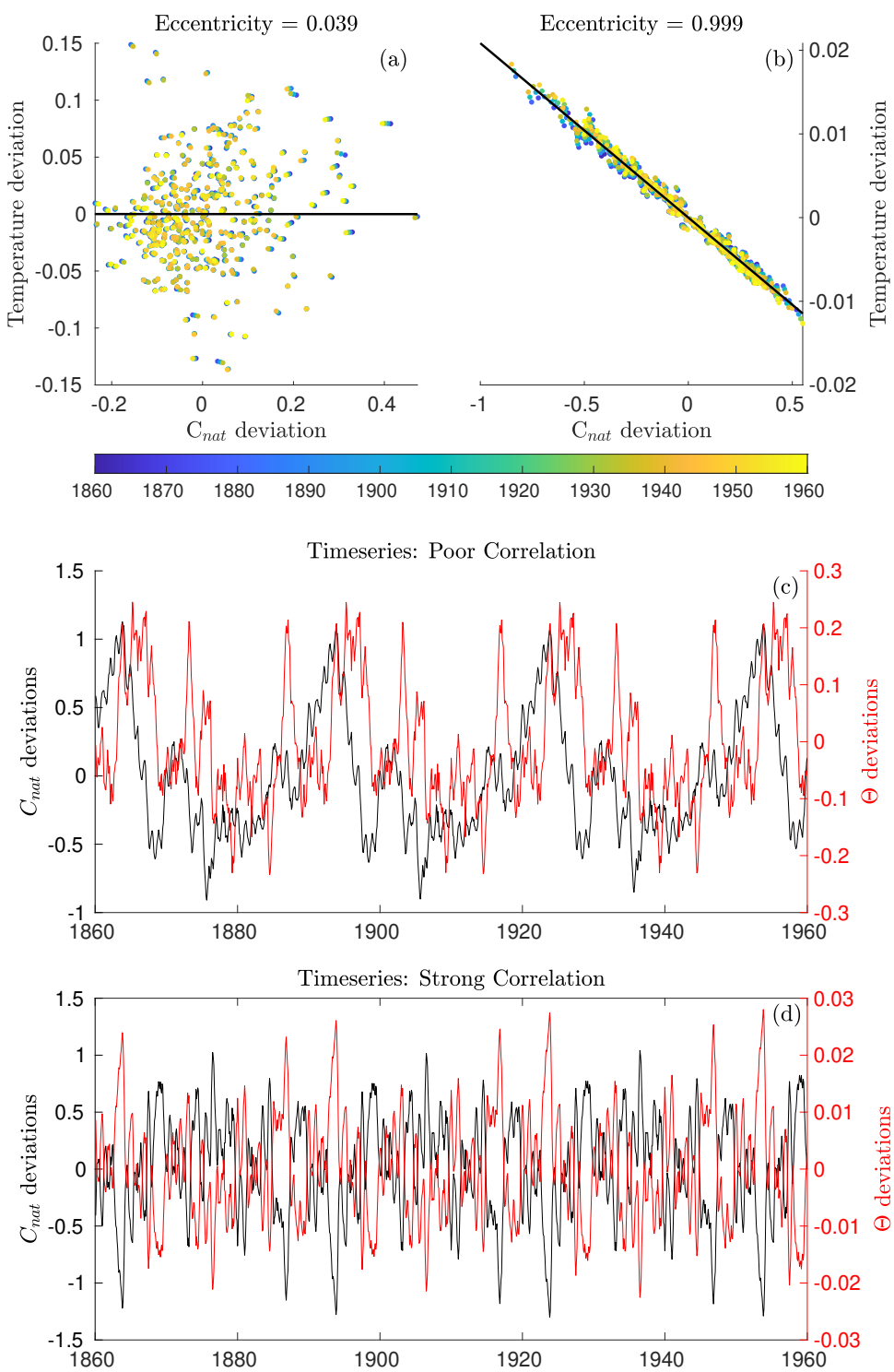

Figure A1. The correlations between $\mathrm{C}_{\text {nat }}$ and $\Theta$ used to establish a $\kappa_{r}$ value, for a poorly correlated point ((a),(c)), and a well correlated point ((b),(d)), in $\Theta-C_{\text {nat }}$ space ((a), (b)), and timeseries of both ((c),(d)). These two points are located at $24 \mathrm{~N}, 30 \mathrm{~W}$ in the Atlantic, at depths of 850 and $1950 \mathrm{~m}$. The major axis of the covariance ellipse in panels (a) and (b) is shown in black. 